10

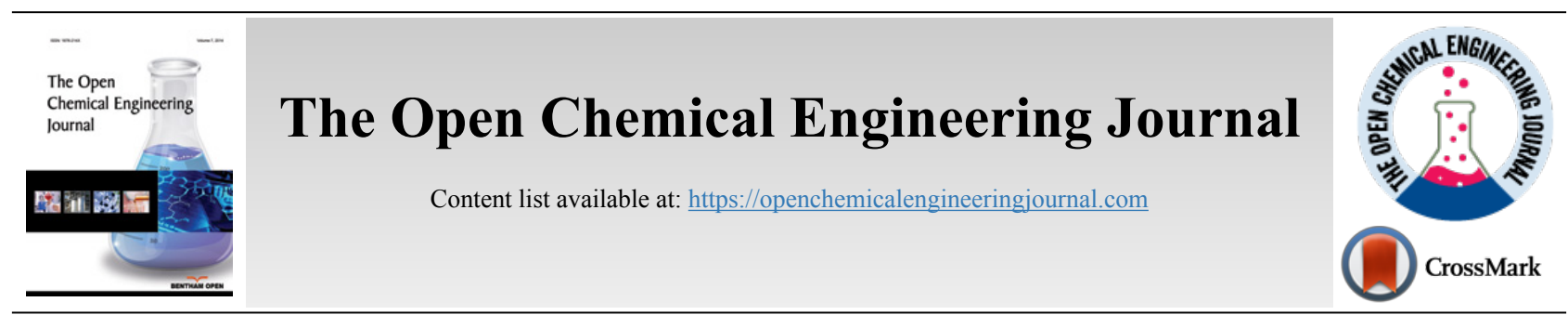

RESEARCH ARTICLE

\title{
Application Of Seeding Crystallization as a Pre-Treatment Stage for The Reduction of Scaling Tendency of Seawater Feed to Thermal Desalination Units
}

\author{
Mazen N. Al-Amaireh", \\ ${ }^{1}$ Tafila Technical University, P.O. Box. 179, Tafila 66110, Jordan
}

\begin{abstract}
:
Objective:

The fouling inhibition in seawater desalination and scale control using crystallization with calcite seeds is evaluated experimentally in this study.

Methods:

The growth kinetic parameters are determined experimentally, correlated and discussed at different operating conditions. Supersaturation levels represent driving force behind the growth of crystals, which is influenced directly by seawater $\mathrm{pH}$ values and temperatures.

Results:

Results indicate that the initial $\mathrm{pH}$ value of seawater must be controlled to be in the range (8-9) and calcite seeds will not have the potential to start the growth process in seawater at the normal $\mathrm{pH}(7.36)$. The growth kinetic parameters are determined from the measured desupersaturation curves.

\section{Conclusion:}

It is found that the growth process of calcite is controlled by the surface integration step. The growth rate of calcite increases with increasing temperature and seeding ratio (up to $1 \mathrm{~g} / \mathrm{L}$ ), while it decreases with increasing the salinity of seawater.
\end{abstract}

Keywords: Seawater, Desalination, Crystallization, Growth rate, Vaterite, Aragonite.

\section{Article History}

Received: January 1, 2021

Revised: May 25, 2021

Accepted: May 31, 2021

\section{INTRODUCTION}

Formation of scaling deposits of sparingly soluble salts on the outer surfaces of hot pipes in Multi Effect Distillation (MED) units represents a severe problem in seawater desalination. These mineral deposits form hard and strongly adhering layers on the metallic surfaces [1 - 3]. Calcium carbonate is the main component ( $98 \%$ of the layer) at a temperature level less than $90{ }^{\circ} \mathrm{C}$ and can be crystallized in three different polymorphs: calcite, aragonite and vaterite. Calcite is the least soluble form and its crystallization on the hot surfaces is enhanced by the decrease of its equilibrium solubility at elevated temperatures in the metastable seawater. The formation of such layers reduces the heat transfer and therefore causes an increase in energy costs with the accompanying problems such as the danger of overheating,

* Address correspondence to this author at the Tafila Technical University, P.O. Box. 179, Tafila 66110, Jordan; Tel: +962.3.2250326; Fax: +962.3.2250431;

E-mail: mazenamaireh@yahoo.com unscheduled shutdown of the unit and corrosion, which leads to deterioration of the metallic pipes of the heat exchangers.

The scaling/fouling inhibit and control in seawater desalination and can be attained successfully through the applications of antifouling agents, where such polymer additives are added constantly with metastable water, which in return results in significant environmental and economic issues that can be problematic later on, in addition to contributing to increased total cost if desalination.

A proposed alternative is separating the scaling materials from seawater by a seeding procedure in a crystallization process. The principle of the seeding technique is based on separating of the sparingly soluble scaling of seawater materials through the process of crystallization at surface of the seed crystals. In the literature, there are many studies (many years back) that reported experimental investigations [4, 5], that tried to find whether it is possible to apply technology of seeding on scale inhibition over an industrial scale. Weth and 
Coury [6] studied the application of seeding methods in falling films plate evaporators for scale inhibition.

Several experimental investigations were conducted by Jones on horizontal pipes evaporators [7] and Rostein and Weinberg [8], which explained the positive findings. In applications of seeding technology, only a low number of studies addressed tubes of horizontal configurations and the majority of reports deal with vertical falling film evaporators and enforced circulation. The researcher was encouraged by scale control results through seeding inside heat exchangers to implement seeding technology on membrane technology [9].

The objective of the study is to contribute to improving scale of control and scale inhibition processes inside thermal desalination plants by seeded crystallization. Seeded batch experiments are conducted to attain the growth kinetic parameters for calcite seeds when growing in seawater. Kinetics of growth is determined by measuring de supersaturation curves in a seeded batch crystallizer under controlled conditions. The factors influencing the kinetics of growth, such as seed type, seeding ration, temperature, supersaturation, $\mathrm{pH}$, and mixing were measured at different salinities of seawater. Calcite seeds are tested as seeds in artificial seawater.

\section{THEORETICAL}

Rate of growth for calcite in seawater is mainly dependent on supersaturation level. The supersaturation $(\boldsymbol{\Omega})$ for calcium carbonate is given through this equation

$$
\Omega=\left[\mathrm{Ca}^{2+}\right]\left[\mathrm{CO}_{3}^{2-}\right] / \mathrm{K}_{s p}
$$

The terms $\left[\mathrm{Ca}^{2+}\right]$ and $\left[\mathbf{C O}_{3}{ }^{2-}\right]$ depict the concentration of calcium and carbonate ions in seawater ( $\mathrm{mol} / \mathrm{kg}$ seawater), respectively, and $\boldsymbol{K}_{s p}$ is the solubility product constant of calcium carbonate in seawater [10]. Consequently, KSP has units of $\mathrm{mol}^{2} / \mathrm{kg}^{2}$ seawater. Seawater is supersaturated with calcium carbonate only when the value of $\Omega$ is more than one, which is the case at its normal salinity and temperature. However, the level of supersaturation is very small and the growth process will take longer time to achieve a measurable or noticeable growth, unless certain measures are taken to increase the driving force for crystal growth which can be attained by controlling the supersaturation in seawater with respect to calcium carbonate.

Several reactions govern supersaturation of calcium ions and carbonate during crystal growth of calcium carbonate in seawater, which happens during crystal growth in seawater. Such reactions produce a carbonate system in the seawater, this is summarized in Fig. (1).

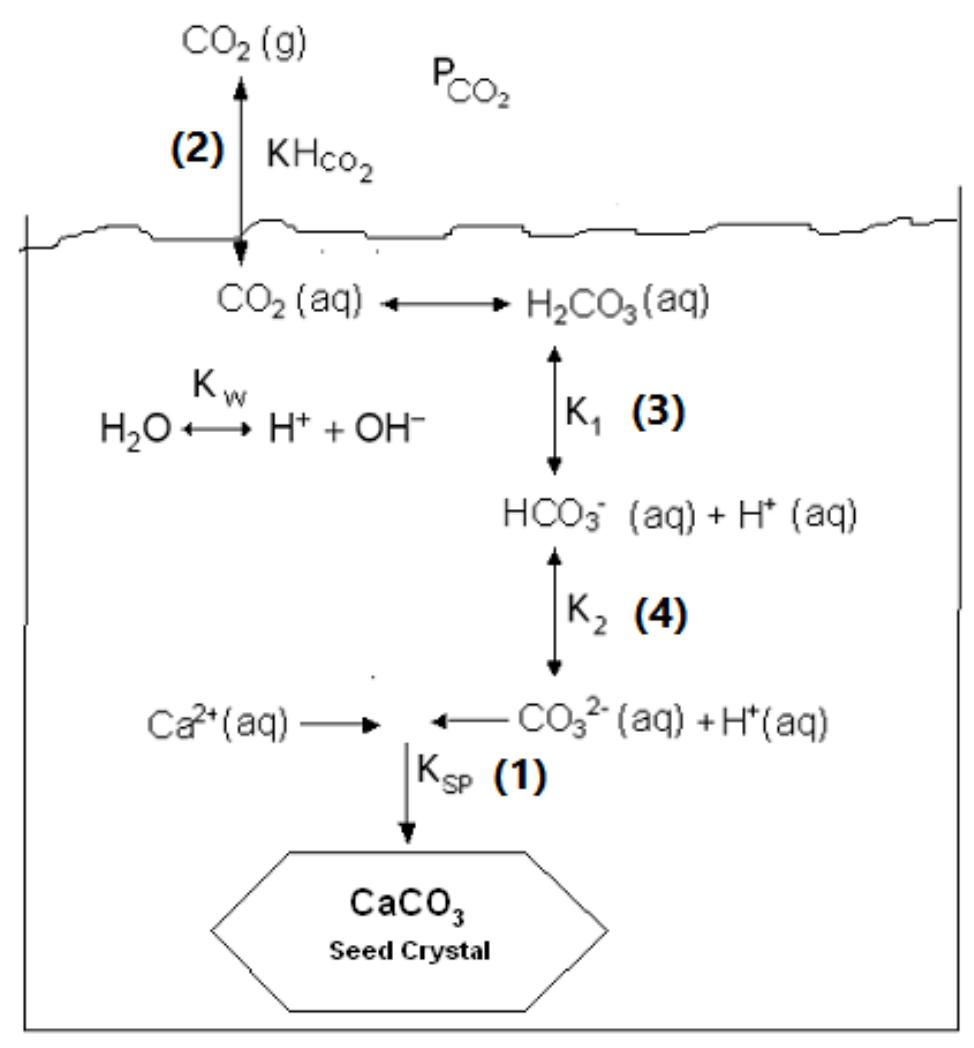

Fig. (1). Equilibrium reactions which take place in seawater during the crystal growth of calcium carbonate seeds: (1) Seeded Crystallization; (2) The liquid-gas equilibria due to the dissolution of carbon dioxide gas in seawater; (3) Dissociation of carbonic acid to bicarbonate ions in seawater (4) dissociation of bicarbonate ions to carbonate ions in seawater. 


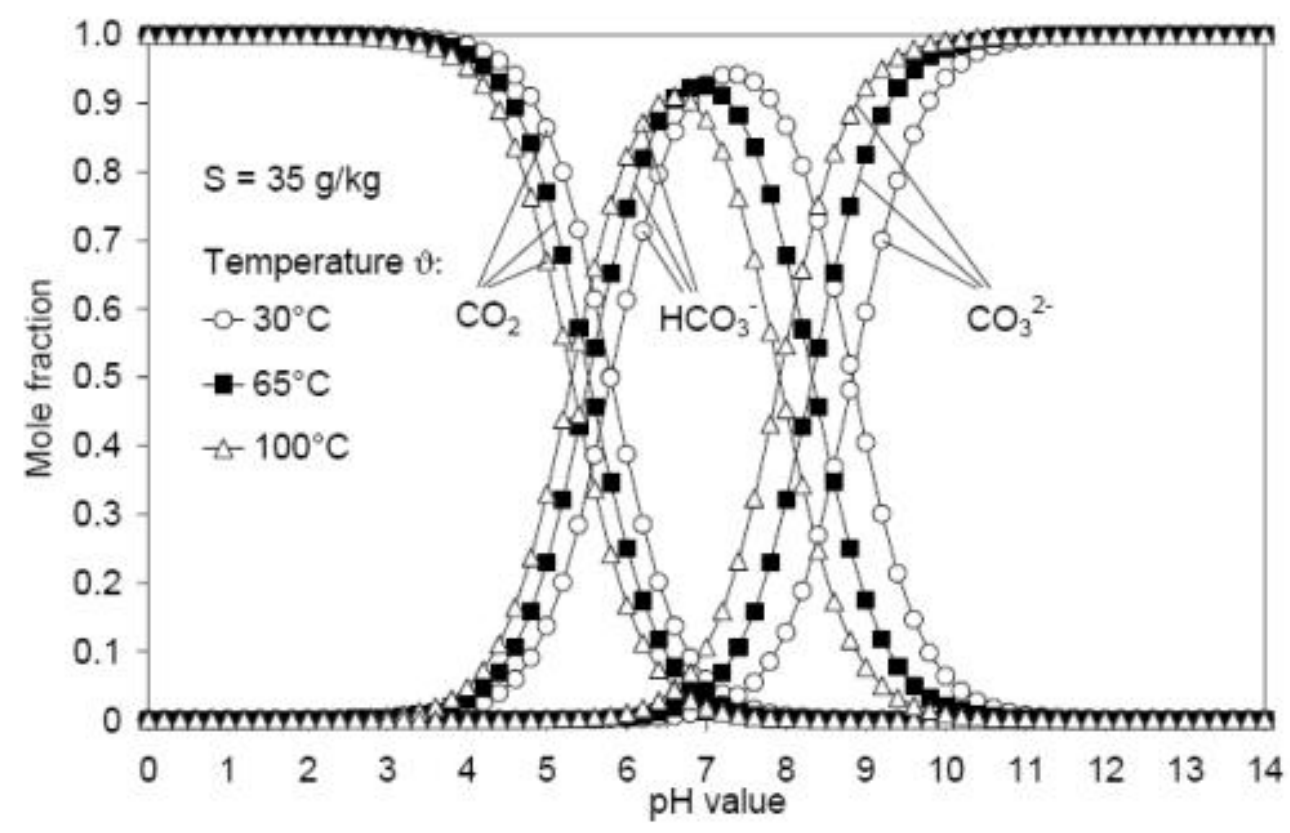

Fig. (2). The mole fractions of $\mathrm{CO} 2, \mathrm{HCO} 3$ - and $\mathrm{CO} 32$ - as a function of $\mathrm{pH}$ for different temperatures at constant salinity of $35 \mathrm{~g} / \mathrm{kg}$ [10].

As shown in Fig. (1), in supersaturated seawater, growth process of calcium carbonate seeds results directly from ion association of carbonate $\left(\mathrm{CO}_{3}^{2-}\right)$ ions and existing calcium $\left(\mathrm{Ca}^{2+}\right)$ ions to form solid $\mathrm{CaCO}_{3}$ based on reaction 1 . The ratio of bicarbonate/carbonate in sea water is affected by a series of equilibrium reactions 2, 3 and 4 (Fig. (1)).

Values of equilibrium constants $\mathrm{Ksp}, \mathrm{KH}_{\mathrm{CO} 2}, \mathrm{Kw}, \mathrm{K} 1$ and $\mathrm{K} 2$ can be estimated as a function of Temperature (T) and salinity (S) using empirical relations in literature. The knowledge of the liquid-liquid and gas-liquid equilibrium in seawater can be used to determine carbonate ion concentration and, the force behind the growth of crystal for calcium carbonate. In seawater, the concentration of carbonate ion depends on the $\mathrm{pH}$ value, temperature and salinity as reported by Millero [7], Fig. (2).

The results shown in Fig. (2) indicate that at constant $\mathrm{pH}$, the mole fraction of $\mathrm{CO}_{2}$ decreases with increasing temperature, whereas the mole fraction of $\mathrm{CO}_{3}{ }^{2-}$ increases. As for values of $\mathrm{pH}$ no more than 7 , mole fraction of $\mathrm{HCO}_{3}^{-}$ elevates for higher temperatures. However, $\mathrm{pH}$ values exceeding 7.5 show less values of $\mathrm{HCO}_{3}{ }^{-}$mole fraction and higher values of mole fraction of carbonate $\left(\mathrm{CO}_{3}{ }^{2-}\right)$ ions. As shown in the figure, $\mathrm{pH}$ values exceeding 7.5 will lead to an increase in $\mathrm{CO}_{3}{ }^{2-}$ and a decrease in $\mathrm{HCO}_{3-}$, accordingly, there will be a consequent increase in the thermodynamic force for the growth of calcine crystals in seawater.

In a closed seeded batch crystallizer, $\left(\mathrm{CO}_{3}{ }^{2-}\right)$ decreases due to the crystal growth of calcium carbonate seeds in the metastable seawater. This is accompanied by a pH-decay as can be understood from the following equation:

$$
\left[\mathrm{CO}_{3}^{2-}\right]=\frac{\mathrm{K}_{1} \mathrm{~K}_{2}\left[\mathrm{H}_{2} \mathrm{CO}_{3}\right]}{\left[\mathrm{H}^{+}\right]^{2}}
$$

Where $\left(\mathrm{H}_{2} \mathrm{CO}_{3}\right)$ and $\left(\mathrm{H}^{+}\right)$are the concentrations of the carbonic acid and hydronium ion in seawater in $\mathrm{mol} / \mathrm{kg}$ seawater. $K_{1}$ in equation 2 is the first thermodynamic dissociation constant of carbonic acid to bicarbonate ions in seawater (mol/kg seawater) whereas $\mathrm{K}_{2}$ is the second thermodynamic dissociation constant of carbonic acid to bicarbonate ions in seawater [7]. If the decrease in $\mathrm{pH}$ (decease in $\left[\mathrm{CO}_{3}{ }^{2-}\right]$ ) over a certain period of time $\mathrm{dt}$ is attributed to the crystal growth, it can be written:

$$
-\frac{d\left[\mathrm{CO}_{3}^{2-}\right]}{d t}=-\frac{d\left[\mathrm{Ca}^{2+}\right]}{d t}=+\frac{d\left[\mathrm{CaCO}_{3}\right]}{d t}
$$

Where $\frac{d\left[\mathrm{CaCO}_{3}\right]}{d t}$ is corresponding to the growth rate of the seeds.

The growth rate data $\left(\mathrm{R}_{\mathrm{m}}\right)$ can be fitted as a function of supersaturation $(\Omega)$ according to the following power law relation:

$$
R_{m}=K_{R} \Omega^{n}
$$

Where $K_{R}$ is the overall rate coefficient which includes both diffusion and surface integration steps and (n) is the overall growth order of seeds. The overall rate coefficient $K_{R}$ is usually temperature dependent according to the Arrhenius equation. 


\section{EXPERIMENTAL SECTION}

As per the data of Millero [10], and for the entire set of experiments, seawater was prepared according to artificial standards and with salinities of $45 \mathrm{~g} / \mathrm{kg}$ and $35 \mathrm{~g} / \mathrm{kg}$. Measurements were carried out in a crystallizer with specific specifications, given that it was closed tightly and jacketed and agitated with a capacity of $500 \mathrm{~cm}^{3}$. In addition, control of temperature $( \pm 0.01 \mathrm{~K})$ was conducted inside the crystallizer through the connection of crystallizer jacket to water feed taken from a programmed thermostat (Julabo-F32). A pH meter was installed to monitor the variation of the $\mathrm{pH}$ value $( \pm$ $0.01)$.

$400 \mathrm{~mL}$ of artificial seawater was added, which was prepared at specific salinity for bath crystallizer within a specific temperature and $\mathrm{pH}$, which led to measuring the growth kinetics. The modifying of seawater $\mathrm{pH}$ took place by using $\mathrm{KOH}$ solid and $\mathrm{HCI}$ solution concentrated. Dried rewashed seeds with fine size $(0-10 \mu \mathrm{m})$ were added to seawater after it reached stable temperatures and $\mathrm{pH}$. Calcite seeds were used for the test. Rate of decay for $\mathrm{pH}$ was recorded as a function of time, then the curves of decay for $\mathrm{pH}$ were implemented to calculate de supersaturation rate over time, given that growth rates are a function of supersaturation.

\section{RESULTS AND DISCUSSION}

\subsection{Calcite Growth Kinetics (Salinity $45 \mathrm{~g} / \mathrm{kg}$ ), Effect of Temperatures}

The measured $\mathrm{pH}$ decay as a function of time at different temperatures is displayed in Fig. (3). The results presented here are related to the growth of calcite seeds in seawater at a salinity of $45 \mathrm{~g} / \mathrm{kg}$. As presented in Fig. (3), the rate of $\mathrm{pH}$ decrease is clearly faster with increasing temperature. The calculated growth rates as a function of supersaturation are shown in Fig. (4). The results presented in Fig. (4) indicate that the growth rate of calcite increases with increasing temperature. Higher temperatures will lead to a decrease in the solubility of calcium carbonate and therefore, the value of Ksp will decrease. Consequently, the level of supersaturation will be higher at elevated temperatures. Moreover, the temperature is a key parameter affecting the carbonate systems and the equilibrium constants ( $\mathrm{K} 1, \mathrm{~K} 2$ and $\mathrm{Ksp}$ ), which has a direct influence on the amount of carbonate ions in seawater. The kinetic parameters of growth are evaluated by the exponential fitting of the results displayed in Fig. (4) according to Eq. 4. The results are summarized in Table $\mathbf{1}$.

Table 1. Kinetic parameters for the growth rate of calcite at the different temperatures studied.

\begin{tabular}{|c|c|c|c|}
\hline $\begin{array}{c}\mathbf{T} \\
{\left[{ }^{\circ} \mathbf{C}\right]}\end{array}$ & $\mathbf{K}_{\mathbf{R}}\left[\mathbf{g} / \mathbf{m}^{2} \cdot \mathbf{s}\right]$ & $\mathbf{n}[-]$ & $\mathbf{R}^{\mathbf{2}}$ (eq. 4) \\
\hline 60 & $2 \times 10^{-6}$ & 2.0541 & 0.9573 \\
\hline 50 & $2 \times 10^{-6}$ & 1.895 & 0.9849 \\
\hline 40 & $2 \times 10^{-6}$ & 1.7229 & 0.9998 \\
\hline 30 & $9 \times 10^{-7}$ & 1.7672 & 0.9384 \\
\hline
\end{tabular}

Results shown in Table $\mathbf{1}$ indicated that as the temperature increases, the growth rate order increases at salinity value of 45 $\mathrm{g} / \mathrm{kg}$. A higher value of rate growth rate order (n) suggests that the integration step to the seed surface turns a more dominant growth step at elevated temperatures. The parameter of growth rate constant $\left(\mathrm{K}_{\mathrm{R}}\right)$ does not change within range of temperature between $40{ }^{\circ} \mathrm{C}$ and $60{ }^{\circ} \mathrm{C}$, while it changes with temperature ranges between $30^{\circ} \mathrm{C}$ and $40^{\circ} \mathrm{C}$.

\subsection{Effect of Salinity Over Calcite Growth Rate}

The decay of $\mathrm{pH}$ is recorded during the growth of calcite seed crystals in synthetic seawater at various salinities. The measured growth rate versus supersaturation at the salinities 35 and $45 \mathrm{~g} / \mathrm{kg}$ are depicted in Fig. (5).

The results presented in Fig. (5) indicate that a faster growth rate is measured at the lower salinity and the difference increases at higher supersaturation. The higher salinity the seawater has, the more dissolved species and, therefore, lower diffusion rate of the calcium and carbonate ions can be found. Also, increasing the salinity will increase the number of ions that can be adsorbed on the growth sites of crystal surfaces of calcite such as magnesium ions. This will contribute to a reduction of the growth rate of calcite at higher salinities.

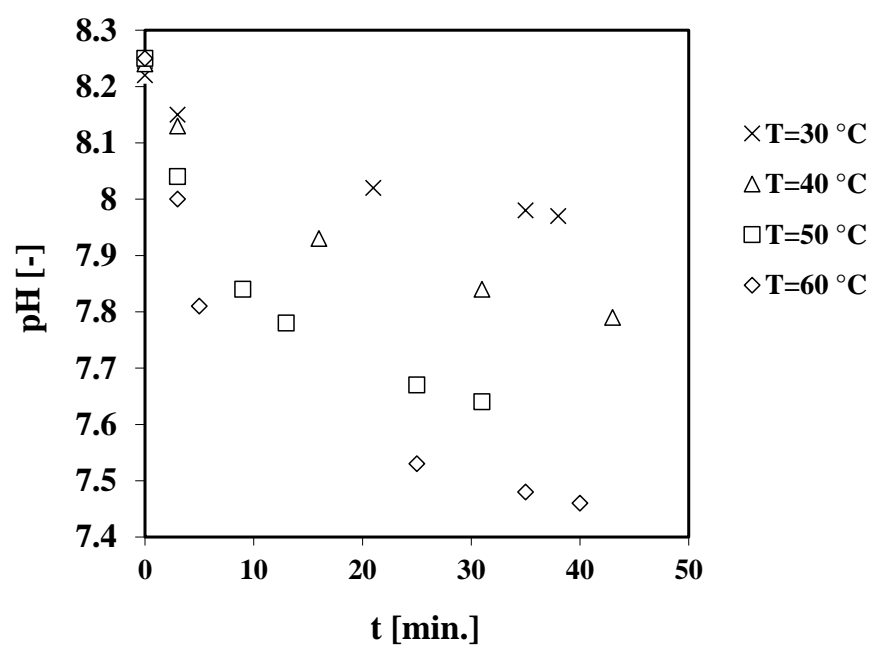

Fig. (3). Recorded decay of $\mathrm{pH}$ as being a function of time at varying temperatures. $\mathrm{pH}$ initial $=8.2, \mathrm{Salinity} \mathrm{S}=45 \mathrm{~g} / \mathrm{kg}, \mathrm{Speed} \mathrm{N}=269 \mathrm{RPM}$, Seeding Ration $\mathrm{SR}=1.0 \mathrm{~g} / \mathrm{l}$. 


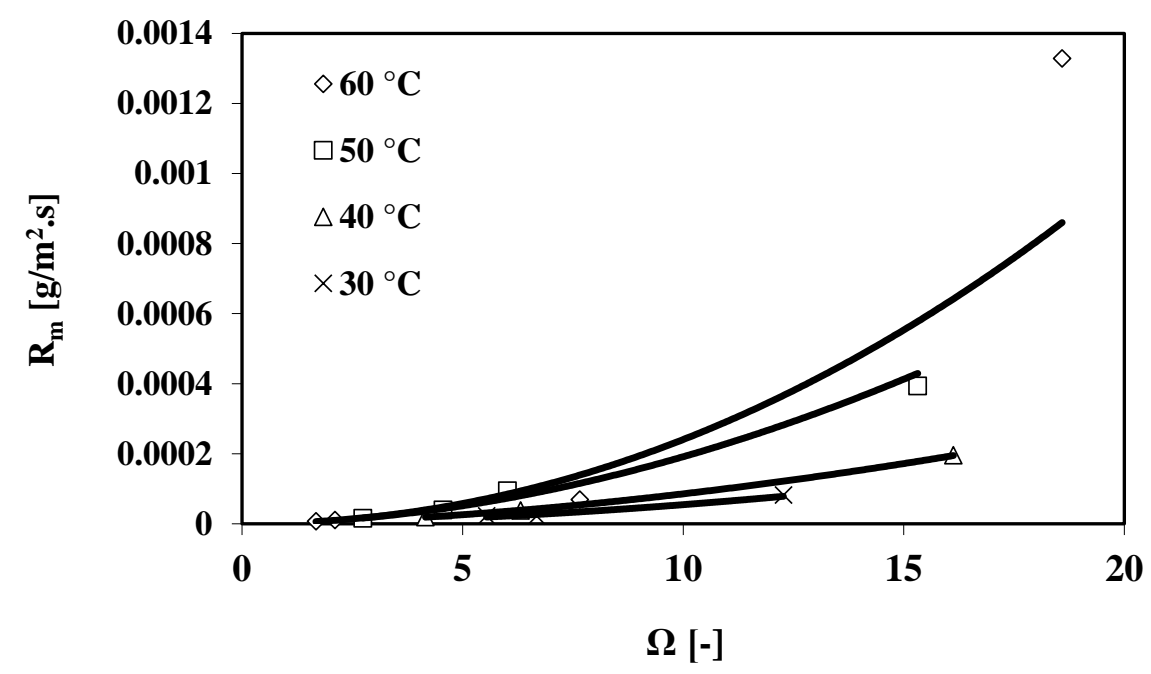

Fig. (4). Rate of growth for calcite versus supersaturation at various temperatures. Salinity $(\mathrm{S})=45 \mathrm{~g} / \mathrm{kg}, \mathrm{pH}$ initial $=8.2$, Ratio of Seeding $\mathrm{SR}=1.0$ $\mathrm{g} / \mathrm{L}$, Speed of Stirrer $(\mathrm{N})=269$ RPM.

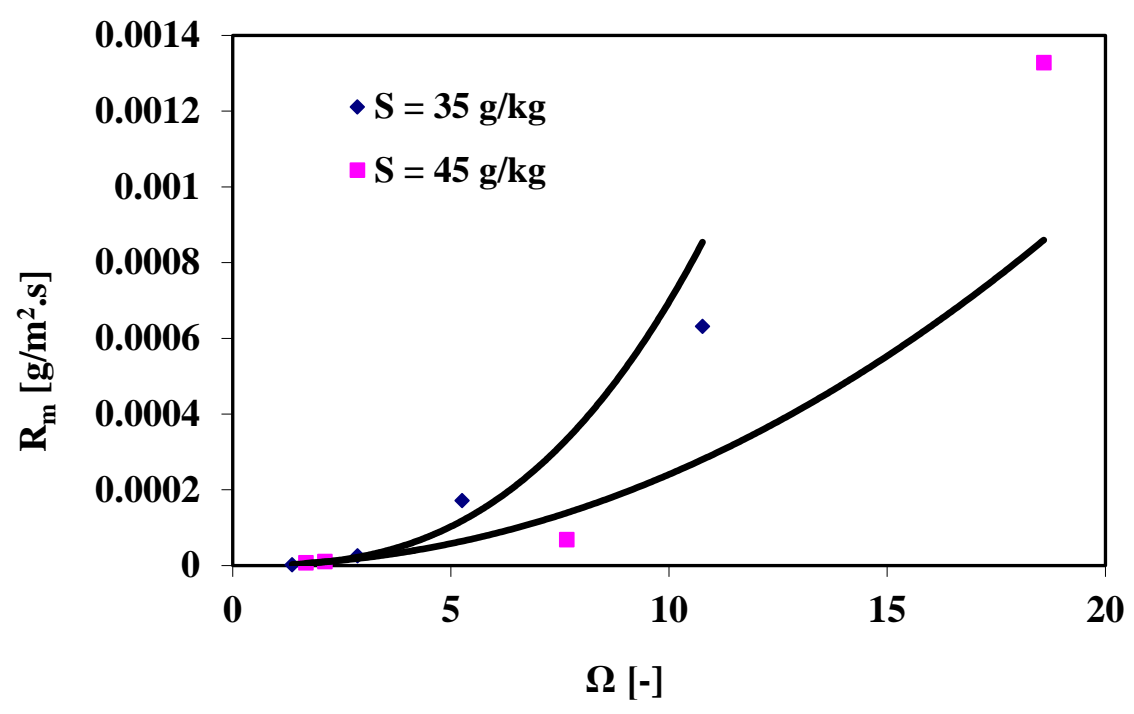

Fig. (5). Calcite growth rate versus supersaturation at various salinities. Temperature $\mathrm{T}=60^{\circ} \mathrm{C}$, initial $\mathrm{pH}=8.2$, Ratio of Seeding $(\mathrm{SR})=1.0 \mathrm{~g} / \mathrm{L}$, Stirrer speed N $=269$ RPM.

\subsection{Stirrer Speed Effect}

Fig. (6) shows the recorded decay of $\mathrm{pH}$ for various stirrer speeds over time which is used to calculate the growth rate at different supersaturation levels presented in Fig. (7).

The results presented in Fig. (7) show a minor effect of stirrer speed on the growth rate of calcite. This indicates that not the diffusion step but the surface integration step is the controlling step of the growth process of calcite in seawater. Also, the stirrer speed has a minor effect on the equilibrium reactions of the carbonate system in seawater which is only dependent on $\mathrm{pH}$ and temperature.

\subsection{Calcite Growth Kinetics in Seawater, the Ratio of Seeding Effect}

Measurements of $\mathrm{pH}$ decay rates were conducted in a batch crystallizer that is seeded at different seeding ratios are presented in Fig. (8). All the measurements were conducted at a fixed temperature $\left(50{ }^{\circ} \mathrm{C}\right)$ and salinity $(35 \mathrm{~g} / \mathrm{kg})$. Fig. (9) shows the calculated growth rates as a function of the seawater supersaturation with respect to calcite. 


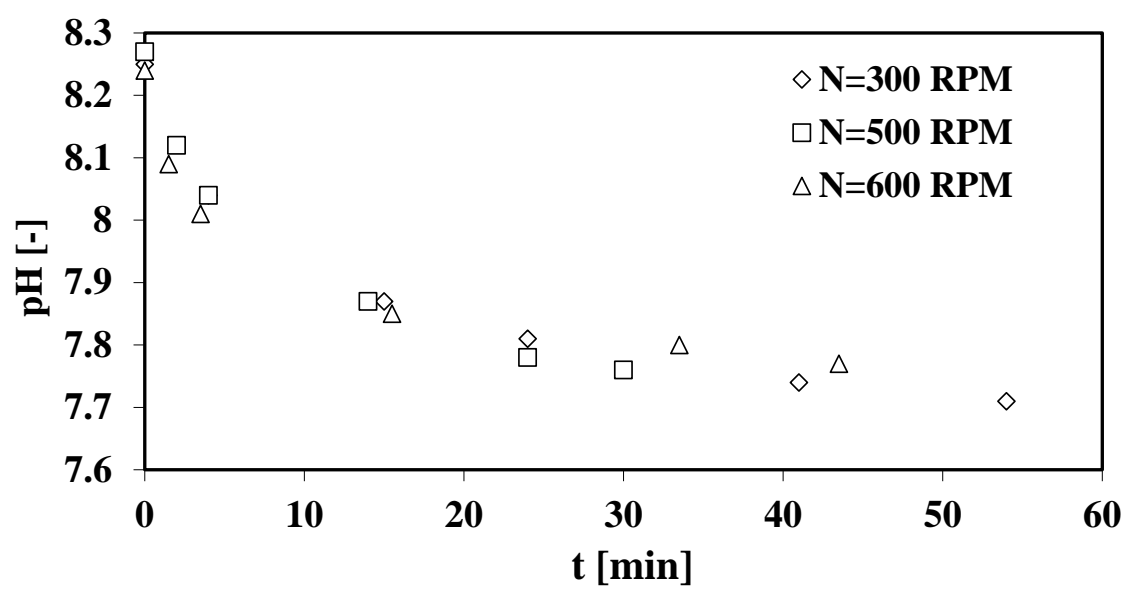

Fig. (6). The measured $\mathrm{pH}$ decay as a function of time at different stirrer speeds. Temperature $(\mathrm{T})=50{ }^{\circ} \mathrm{C}$, Seeding Ratio $\mathrm{SR}=1.0 \mathrm{~g} / \mathrm{L}, \mathrm{Initial} \mathrm{pH}=$ 8.2 , Salinity $(\mathrm{S})=35 \mathrm{~g} / \mathrm{kg}$.

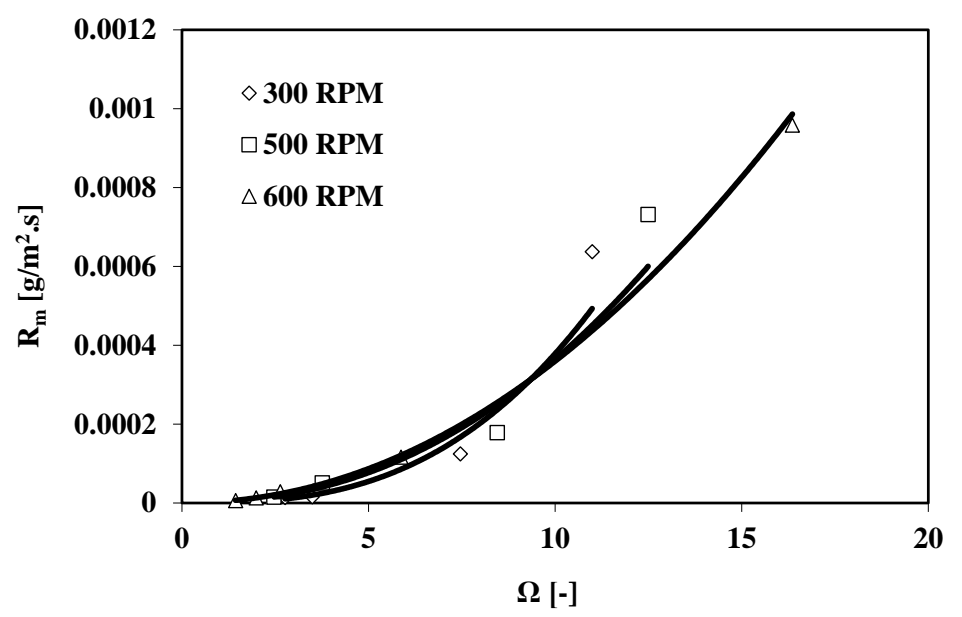

Fig. (7). Growth rate of calcite as a function of supersaturation at different stirrer speeds. Temperature $(\mathrm{T})=50{ }^{\circ} \mathrm{C}$, Seeding Ratio $\mathrm{SR}=1.0 \mathrm{~g} / \mathrm{L}$, Initial $\mathrm{pH}=8.2$, Salinity $(\mathrm{S})=35 \mathrm{~g} / \mathrm{kg}$.

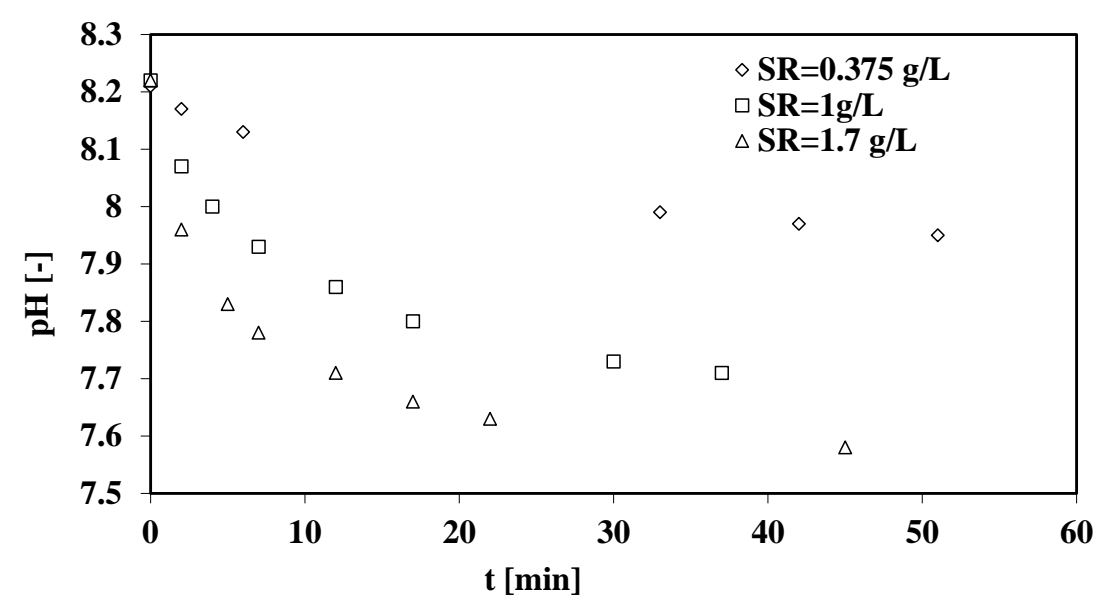

Fig. (8). The measured rate of $\mathrm{pH}$ decline at different seeding ratios. Stirrer Speed $(\mathrm{N})=269 \mathrm{RPM}$, Temperature $(\mathrm{T})=50^{\circ} \mathrm{C}$, Initial $\mathrm{pH}=8.2$, Salinity $(\mathrm{S})=35 \mathrm{~g} / \mathrm{kg}$. 


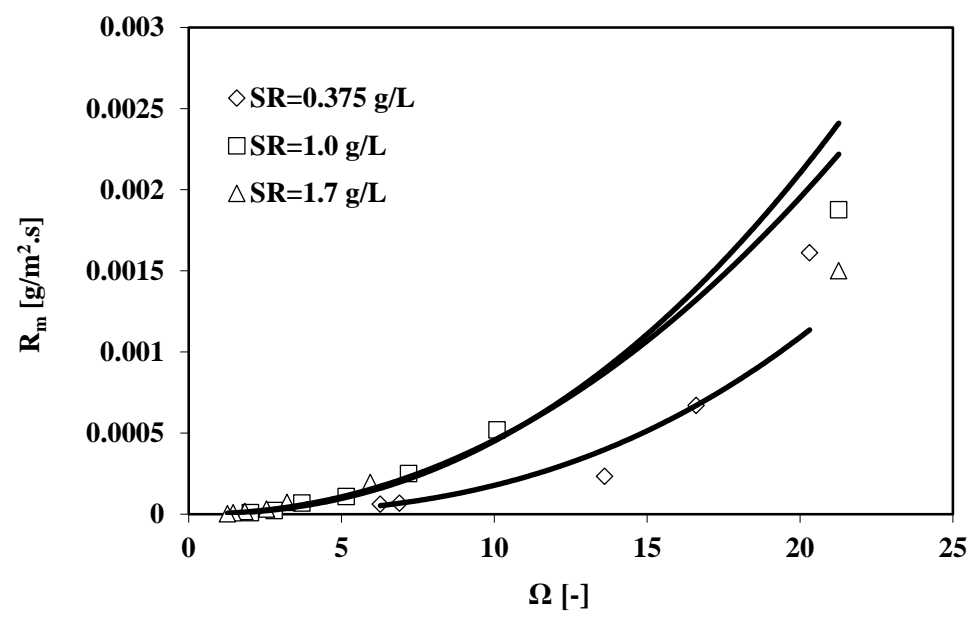

Fig. (9). The calculated Growth rate of calcite as a function of supersaturation at different seeding ratios from the experimental $\mathrm{pH}$ decay shown in Fig. (8).

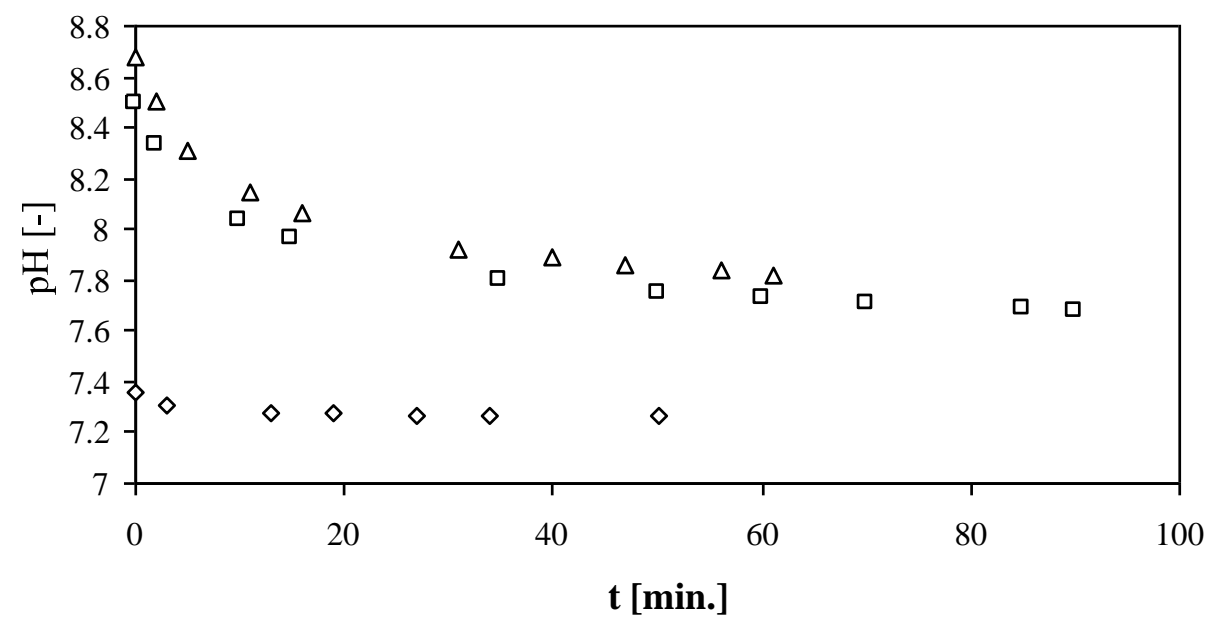

Fig. (10). The measured influence of the initial $\mathrm{pH}$ on the rate of initial $\mathrm{pH}$-decay during crystal growth in seawater. Salinity $(\mathrm{S})=35 \mathrm{~g} / \mathrm{kg}$, Stirrer Speed $(\mathrm{N})=269 \mathrm{RPM}$, Seeding Ratio $(\mathrm{SR})=1 \mathrm{~g} / \mathrm{L}$, Temperature $(\mathrm{T})=50{ }^{\circ} \mathrm{C}$.

From Fig. (9) above, the results suggested that increasing the ratio of seeding from 0.375 to $1 \mathrm{~g} / 1$ will lead to an increase in the rate of growth of calcite. Nonetheless, there is a negligible effect on the rate of growth when the ratio of seeding increases further. Moreover, at higher seeding ratios, the rapid rate of mass deposition is caused by the enlarged existing surface area of the crystal growth.

\subsection{Influence of the initial $\mathrm{pH}$ in seawater on initial growth rate.}

Experiments were conducted to test how the initial values of $\mathrm{pH}$ in seawater influence the initial rate of $\mathrm{pH}$ decay amid the crystal growth for the seeds under definite conditions of temperature, stirrer speed, seeding ratio, and seeds type. The measurements of the $\mathrm{pH}$ decay rate, which indicates the initial seed growth rate at $50{ }^{\circ} \mathrm{C}$ for the normal seawater without adjustment of initial $\mathrm{pH}(\mathrm{pH}=7.36)$ and at the adjusted higher $\mathrm{pH}$ values are shown in Fig. (1).

The experimental data which are depicted in Fig. (10) indicate that seeds of calcite lack the ability of starting growth processes at $\mathrm{pH}$ (7.36) in seawater, giving that the increments of initial value of $\mathrm{pH}$ above 8.4 (see the upper data points of Fig. (10) will lead to faster initial $\mathrm{pH}$ decay, thus faster initial growth rates. As a result, to achieve an appreciable growth of seeds of calcite inside the seawater, therefore, the values of the $\mathrm{pH}$ must be adjusted to be higher than or at least 8.0. These results are in good agreement with the theoretical calculations shown in Fig. (2).

\section{CONCLUSION}

Crystallization with seeding can be implemented successfully to control the scaling process thermal seawater desalination units if the process parameters and the kinetic data are well understood. This study represents the starting stage to replace the already existing methods based on dosing antiscaling chemicals with a reliable, economical and low environmental impact method based on physical separation of scaling minerals by crystallization. Further studies to develop its industrial application are recommended.

\section{CONSENT FOR PUBLICATION}

Not applicable. 


\section{AVAILABILITY OF DATA AND MATERIALS}

Not applicable.

\section{FUNDING}

None.

\section{CONFLICTS OF INTEREST}

The authors declare no conflict of interest, financial or otherwise.

\section{ACKNOWLEDGEMENTS}

Declared none.

\section{REFERENCES}

[1] C. Xie, L. Zhang, Y. Liu, Q. Lv, G. Ruan, and S.S. Hosseini, "A direct contact type ice generator for seawater freezing desalination using LNG cold energy", Desalination, vol. 435, pp. 293-300, 2018. [http://dx.doi.org/10.1016/j.desal.2017.04.002]

[2] Y. Liu, T. Ming, Y. Wu, R. de Richter, Y. Fang, and N. Zhou, "Desalination of seawater by spray freezing in a natural draft tower", Desalination, vol. 496, no. 114700, 2020
[3] P. Sahu, S. Krishnaswamy, and N.K. Pande, "Process intensification using a novel continuous U-shaped crystallizer for freeze desalination", Chem. Eng. Process., vol. 153, no. 107970, 2020.

[4] R. Bond, S. Veerapaneni, and E. Brandt, "Reducing Costs of Inland Desalination ZLD treatment", J. Am. Water Works Assoc., vol. 3, pp. 56-59, 2005. [http://dx.doi.org/10.1002/j.1551-8833.2005.tb10843.x]

[5] F.C. Standiford, and J.R. Sinek, "Stop scale in seawater evaporators", Chem. Eng. Prog., vol. 57, no. 1, pp. 58-63, 1961.

[6] G.E. Coury, and G. Weth, "Seeding techniques for scale prevention in water treatment systems", Proc. Nat. Conf. on Water Ruse, AIChE, vol. vol. 5, 1973pp. 116-124

[7] J.E. Jones, Seeding of Brackish water in a spray film evaporator., USArmy Mobility Equipment Research and Development Center USAMERDC, 1970.

[8] "Operation of horizontal tube brine concentrator", Desalination, vol. 40, pp. 159-168, 1982

[http://dx.doi.org/10.1016/S0011-9164(00)88679-8]

[9] R.J. Sikora, "Brine concentrator and seeded reverse osmosis", 13th Austral. Chem. Eng. Conf., 1985pp. 33-40 Path, Australia

[10] F.J. Millero, Chemical Oceanography., $2^{\text {nd }}$ ed CRC press: Boca Raton, 1996.

[11] M.P. Hain, D.M. Sigman, J.A. Higgins, and G.H. Haug, "The effects of secular calcium and magnesium concentration changes on the thermodynamics of seawater acid/base chemistry: Implications for Eocene and Cretaceous ocean carbon chemistry and buffering", Global Biogeochem. Cycles, vol. 29, no. 5, pp. 517-533, 2015. [http://dx.doi.org/10.1002/2014GB004986]

\section{C) 2021 Mazen N. Al-Amaireh.}

This is an open access article distributed under the terms of the Creative Commons Attribution 4.0 International Public License (CC-BY 4.0), a copy of which is available at: (https://creativecommons.org/licenses/by/4.0/legalcode). This license permits unrestricted use, distribution, and reproduction in any medium, provided the original author and source are credited. 